\title{
Srečanje fitopatologov ob vdoru nove bolezni v Evropo: bolezen tisoč- erih rakov, ki jo povzroča gliva Geosmithia morbida in njen vektor Pityophthorus juglandis
}

\section{Dušan JURC *}

V septembru 2013 so opazili naglo sušenje črnih orehov (Juglans nigra L.) v nasadih pri vasici Bressanvido blizu Vicenze (severna Italija). Gozdni fitopatolog iz Univerze v Padovi prof. Lucio Montecchio je ugotovil, da je vzrok za množično odmiranje dreves bolezen tisočerih rakov (angl. »thousand cankers disease «), ki jo povzroča gliva Geosmithia morbida Kolařik (Ascomycota, Hypocreales), prenaša pa jo orehov vejni lubadar Pityophthorus juglandis Blackman 1928 (Coleoptera, Scolytinae) (Montecchio in Faccoli, 2014). Bolezen se kljub ostrim karantenskim ukrepom naglo širi v ZDA od sredine devetdesetih let, povzroča množično sušenje več vrst orehov, ki so razširjeni v Severni Ameriki in tam je bila ugotovljena tudi na navadnem orehu (Juglans regia L.), ki ga bolezen v zadnjem času kuži vedno močneje (Utley in sod., 2013). Zato pomeni prenos glive in njenega vektorja v Evropo veliko potencialno nevarnost za gojenje navadnega oreha in drugih (tujerodnih) vrst orehov pri nas in zato sta bila gliva in njen vektor hitro po vnosu v Evropo uvrščena v EPPO opozorilni seznam (EPPO, 2014).

Gozdni fitopatologi sosednjih držav prof. dr. Lucio Montecchio (Italija), prof. dr. Danko Diminić (Hrvaška), prof. dr. Thomas Cech (Avstrija) in prof. dr. Dušan Jurc (Slovenija) smo si zaradi pomembnosti najdbe 26. in 27. 6. 2014 ogledali žarišče bolezni (slika 1). Množično odmirajo pribl. 17 let stari črni orehi v nasadu hitrorastočih listavcev (slika 2) in posamična, približno 80 let stara drevesa v bližnjem parku (slika 3). Črni oreh sadijo v Padski nižini v velikem številu, saj izredno hitro prirašča in daje dragocene sortimente, zelo pogost pa je tudi pravi oreh, ki ga sadijo za pridelavo plodov. V vročem in soparnem vremenu smo opazovali gomazenje številnih majhnih podlubnikov ( $P$. juglandis), ki smo jih vznemirili z lupljenjem skorje pri iskanju simptomov bolezni tisočerih rakov na odmirajočih drevesih.

\section{Zgodovina, simptomi in potek bolezni}

Gliva Geosmithia morbida je bila opisana šele leta 2011 (Kolařík, 2011), vendar je bila njena patogenost in obligatna povezava $\mathrm{z}$ orehovim vejnim lubadarjem (Pityophthorus juglandis) znana že nekaj let prej (Tisserat in sod., 2009). Naravna razširjenost povzročiteljice bolezni in njenega vektorja je jugozahod ZDA, kjer je bolezen dokaj neškodljiva za domorodne vrste Juglans major in J. californica. Od tam so ju sredi devetdesetih let prenesli najverjetneje $\mathrm{z}$ okuženo hlodovino proti severu in v centralne dele ZDA, kjer rastejo druge vrste orehov in predvsem zelo občutljiv in gospodarsko pomemben črni oreh (Zorillo in sod., 2014) in tam je bolezen nato pričela povzročati pomembne škode $\mathrm{v}$ gozdovih in $\mathrm{v}$ urbanih predelih.
Bolezen tisočerih rakov je značilna po nekaterih posebnostih, ki jih pri drugih boleznih drevja ne opazimo. Gliva Geosmithia morbida oblikuje ogromno število konidijev, ki jih raznaša veter, vendar ti ne morejo povzročiti okužbe. V skorjo zdravih dreves dolbejo rove orehovi vejni lubadarji in prenašajo trose zajedavske glive, če so se razvili in izlegli v drevesih, okuženih z boleznijo tisočerih rakov. Ti trosi v skorji kalijo in gliva povzroči odmiranje skorje v obliki rjavih, do $20 \mathrm{~cm}$ dolgih lečastih nekroz (slika 4, slika 5, slika 6). Gliva ni zelo patogena in nekroze ostanejo lokalizirane, vendar je napad lubadarjev običajno zelo močan, tako, da se na vejah in deblu pojavi na tisoče odmirajočih predelov skorje, ki se združujejo in v končni fazi odmre vsa skorja in kambij (slika 7). Po tem znamenju je bolezen dobila ime »bolezen tisočerih rakov«. Gliva se ne razrašča v lesu, odmira samo skorja, vendar zaradi množičnosti nekroz začno veneti in se sušiti listi na posamičnih vejah v krošnji, odmiranje hitro zajame celo krošnjo in drevo odmre $\mathrm{v}$ eni ali dveh rastnih obdobjih. Orehov vejni lubadar je zelo majhen hrošček, dolg je le 1,5 do 2 mm (slika 8, slika 9). Je edina vrsta podlubnika, ki naseljuje orehe, njegova značilnost so drobne grbice na vratnem ščitu, razporejene v štiri do šest polkrožnih vrst ter pokrovke zadka se na koncu strmo spuščajo (slika 10).

Na bolezen sta zelo občutljiva črni oreh (Juglans nigra) in sivi oreh (J. cinerea), srednje so občutljivi navadni oreh (J. regia), in nekatere ameriške vrste oreha $(J$. hindsii, J. californica, J. microcarpa), zelo pa je odporen arizonski oreh (J. major). Poleg orehov pa so bolezen tisočerih rakov z umetnimi okužbami prenesli tudi na nekatere oreškarje (Carya ovata, C. illinoinensis), ki lahko v prihodnosti predstavljajo vir okužbe v mešanih sestojih z orehi (Utley in sod., 2013). Zatiranje bolezni temelji na higienskih ukrepih in preprečevanju namnožitve vektorja. Karantenski ukrepi vključujejo prepoved prevoza lesa z lubjem (npr. hlodovina in les za ogrevanje) in takojšnje uničenje vseh napadenih delov odmirajočih dreves.

Žarišče bolezni v Italiji ni obsežno in nerazumljivo je, da italijanska fitosanitarna služba v več kot letu dni od ugotovitve bolezni še ni storila ničesar za njeno izkoreninjenje. Zato moramo biti pri nas pozorni na nenadno odmiranje vej ali celih dreves črnega oreha in natančno pregledati vsako sumljivo odmiranje vej navadnega oreha. Obstaja namreč nevarnost, da bosta gliva in njen vektor prenesena $v$ Slovenijo. Zato vas pozivamo, da nas obvestite, v kolikor opazite opisane simptome bolezni tisočerih rakov. Naslov za obveščanje: Laboratorij za varstvo gozdov, Gozdarski inštitut Slovenije, Večna pot 2, 1000 Ljubljana, telefon: (01) 200-78-24. 


\section{Zahvala}

Zahvaljujemo se prof. dr. Luciu Montecchiu iz Univerze v Padovi za povabilo in terenski ogled prizadetih sestojev črnega oreha.

\section{Viri}

EPPO 2014. Thousand cankers disease - Geosmithia morbida and Pityophthorus juglandis. http://www.eppo.int/QUARANTINE/Alert List/fungi/Geosmithia_morbida.htm (20.1. 2015)

Kolařík M., Freeland E., Utley C., Tisserat N. 2011. Geosmithia morbida sp. nov., a new phytopathogenic species living in symbiosis with the walnut twig beetle (Pityophthorus juglandis) on Juglans in USA. Mycologia 103: 325-332.

Montecchio L., Faccoli M. 2014. First record of thousand cankers disease Geosmithia morbida and walnut twig beetle Pityophthorus juglandis on Juglans nigra in Europe. Plant Dis. 98: 696.

Tisserat N., Cranshaw W., Leatherman D., Utley C., Alexander K. 2009. Black walnut mortality in Colorado caused by the walnut twig beetle and Thousand cankers disease. Plant Health Progress. http://www.plantmanagementnetwork.org/pub/php/rese$\operatorname{arch} / 2009 /$ walnut/ (21. 1. 2015)

Utley C., Nguyen T., Roubtsova T., Coggeshall M., Ford T.M., Grauke L.J., Graves A.D., Leslie C.A., McKenna J., Woeste K., Yaghmour M.A., Cranshaw W., Seybold S.J., Bostock R.M., Tisserat N. 2013. Susceptibility of walnut and hickory species to $\mathrm{Ge}$ osmithia morbida.

Plant Dis. 97:601-607.

Zerillo M.M., Ibarra Caballero J., Woeste K., Graves A.D., Hartel C., et al. 2014. Population structure of Geosmithia morbida, the causal agent of thousand cankers disease of walnut trees in the United States. PLoS ONE 9(11): e112847. doi:10.1371/journal.pone.0112847

*Gozdarski inštitut Slovenije, Večna pot 2, 1000 Ljubljana dusan.jurc@gozdis.si

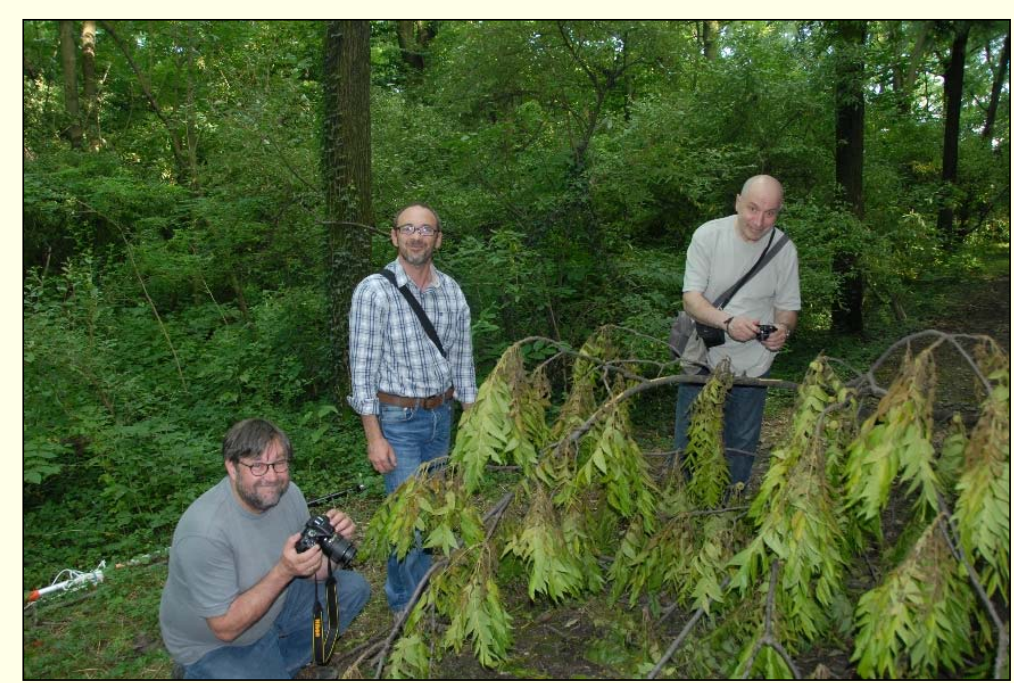

Slika 1: Pregled okuženih vej črnega oreha: (od leve) prof. dr. Thomas Cech, prof. dr. Lucio Montecchio in prof. dr. Danko Diminić (foto: D. Jurc)

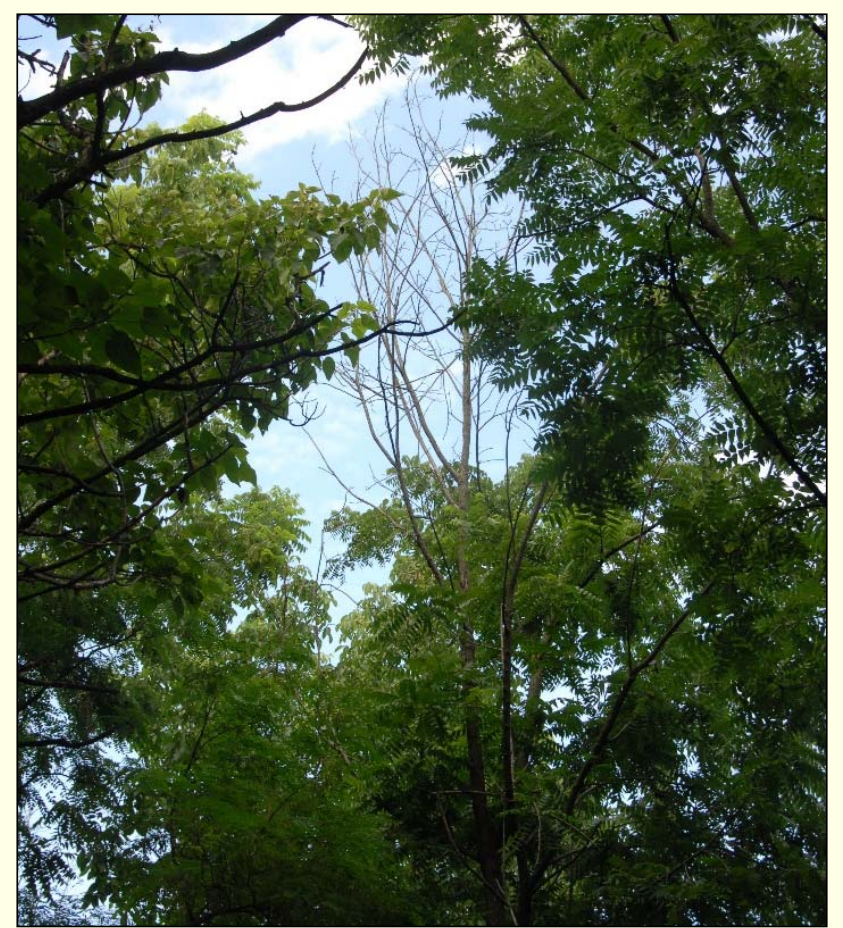

Slika 2: Mlado drevo črnega oreha je uničila bolezen tisočerih rakov (foto: D. Jurc) 


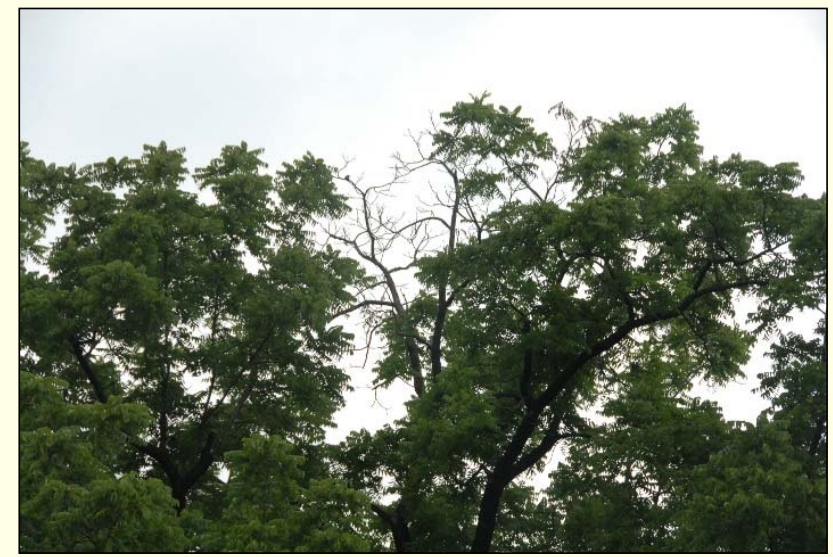

Slika 3: Zaradi bolezni tisočerih rakov se suši vrh odraslega črnega oreha (foto: D. Jurc)

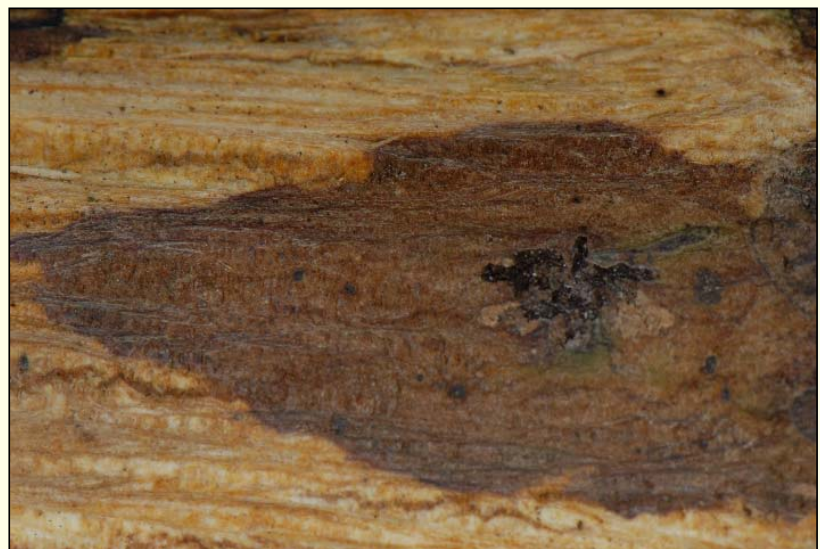

Slika 5: Rovi orehovega vejnega lubadarja in nekroza skorje (zgornja plast skorje je odstranjena) (foto: D. Jurc)

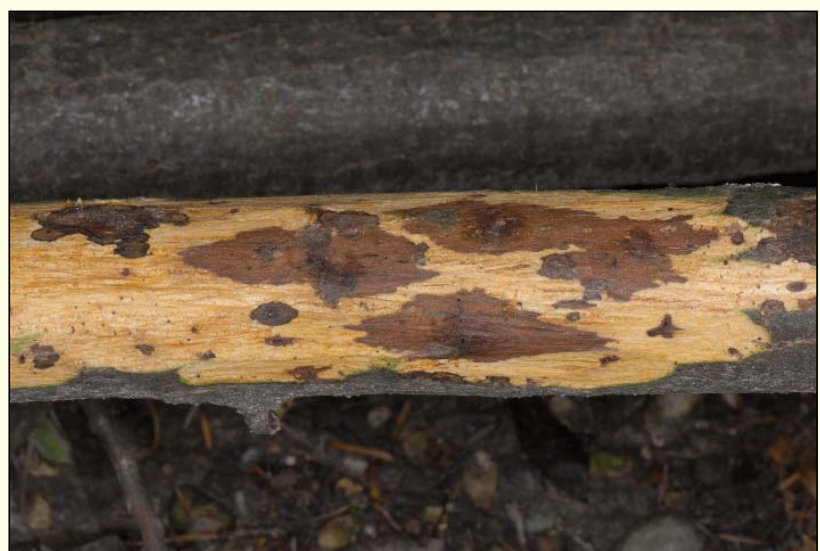

Slika 7: Množičen napad lubadarjev povzroči množico nekroz skorje na veji (foto: D. Jurc)

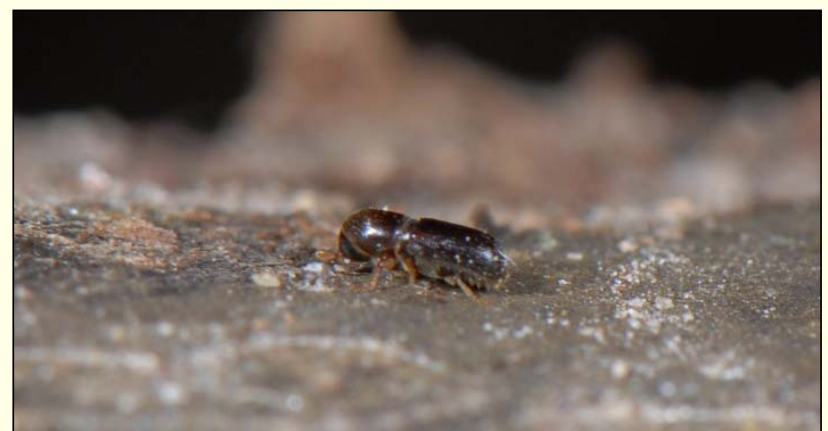

Slika 9: Orehov vejni lubadar od strani (foto: D. Jurc)

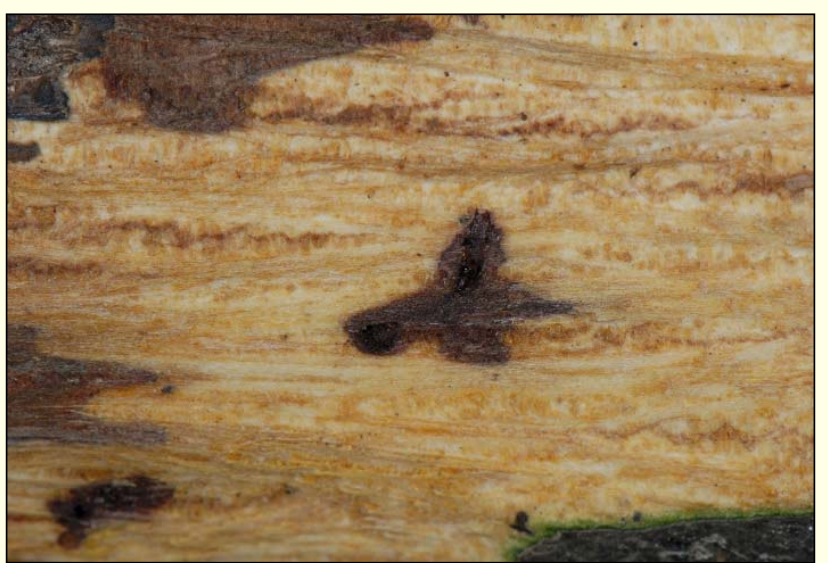

Slika 4: Orehov vejni lubadar dolbe rove v skorjo in gliva Geosmithia morbida začenja povzročati odmiranje in rjavenje skorje (zgornja plast skorje je odstranjena) (foto: D. Jurc)

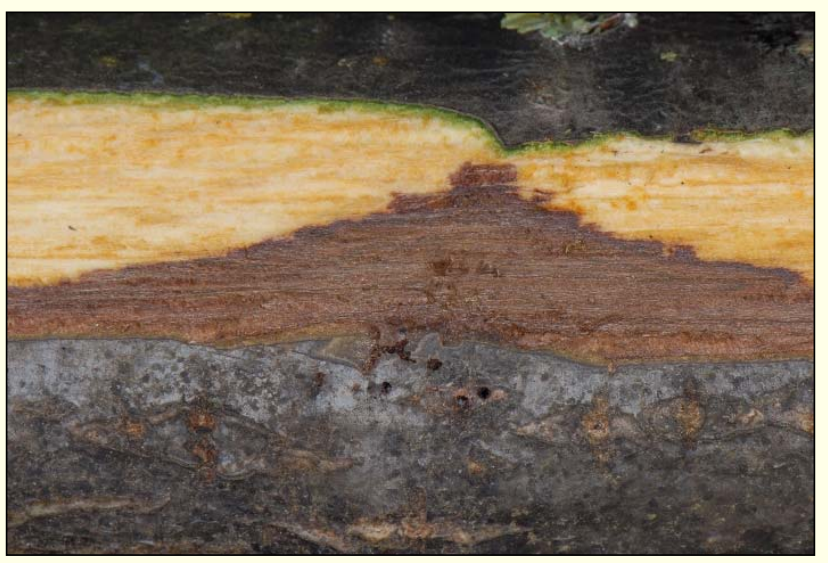

Slika 6: Na nepoškodovani površini skorje so izhodne odprtine orehovega vejnega lubadarja, na olupljenem delu je rjava odmrla skorja (foto: D. Jurc)

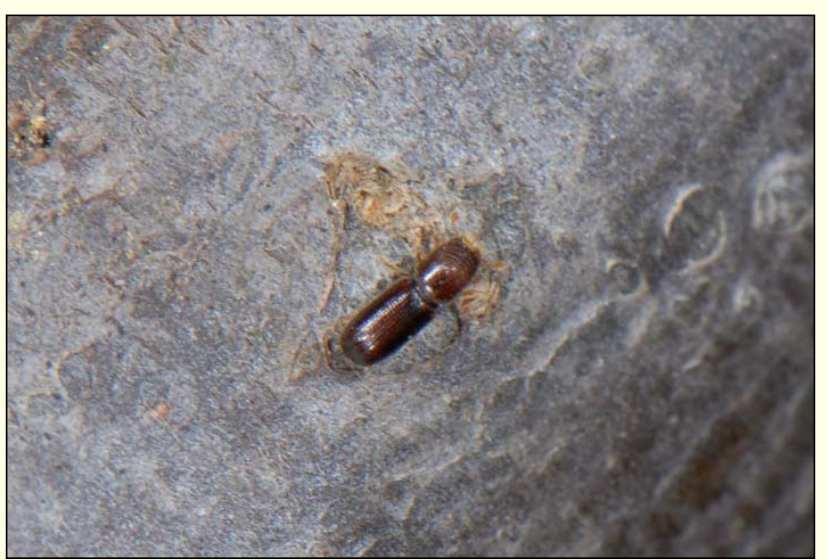

Slika 8: Orehov vejni lubadar (Pityophthorus juglandis) je 1,5 do $2 \mathrm{~mm}$ dolg hrošček (foto: D. Jurc)

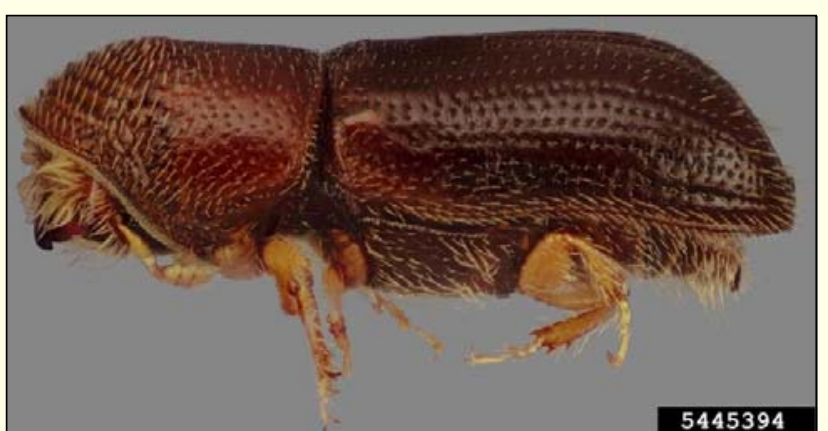

Slika 10: Orehov vejni lubadar (foto: Steven Valley, Oregon Department of Agriculture, Bugwood.org) 